$98: 8^{\circ}$, and the pulse was seldom as high as 100 , and never above it. The child is now a sturdy little boy over twelve months old.

I fear Dr. Godson must add this case as an unsuccessful one to his list. Yet I think the death would be more fairly credited to the disease that remained than to the operation, though at the time it was ascribed, in part at least, to carbolic acid poisoning. It was, of course, unsatisfactory to be obliged to leave the epitheliomatous cervix, but the patient was in such an exhausted condition, that to have removed it would have been immediately fatal. Even Porro's operation had to be performed with a rapidity which, without efficient assistance, would have been impossible.

\section{EXTROVERSION OF BLADDER.}

BY A. W. MAYO ROBSON, F.R.C.S. Surgeon to the Leeds General Infirmary; Lecturer on Operative Surgery at the
Yorkshire College.

The following notes and drawings have been kindly furnished me by my house-surgeon, Mr. Herbert Child.

L. S., female, aged 8, was admitted on February 8th, 1884, suffering from complete ectropion vesice. The abdominal wall was wanting from the umbilicus to the pubes, while the orifices of the ureters were to be seen at the lower part of the triangular patch of vesical mucous membrane. On March 3rd was performed Wood's plastic operation for the deformity. Mr. Robson took a large square flap from the abdominal wall above the umbilicus, and turned it downwards, so that the cutaneous surface come into contact with exposed vesical mucous membrane. Pyriform flaps, one on each side, were taken

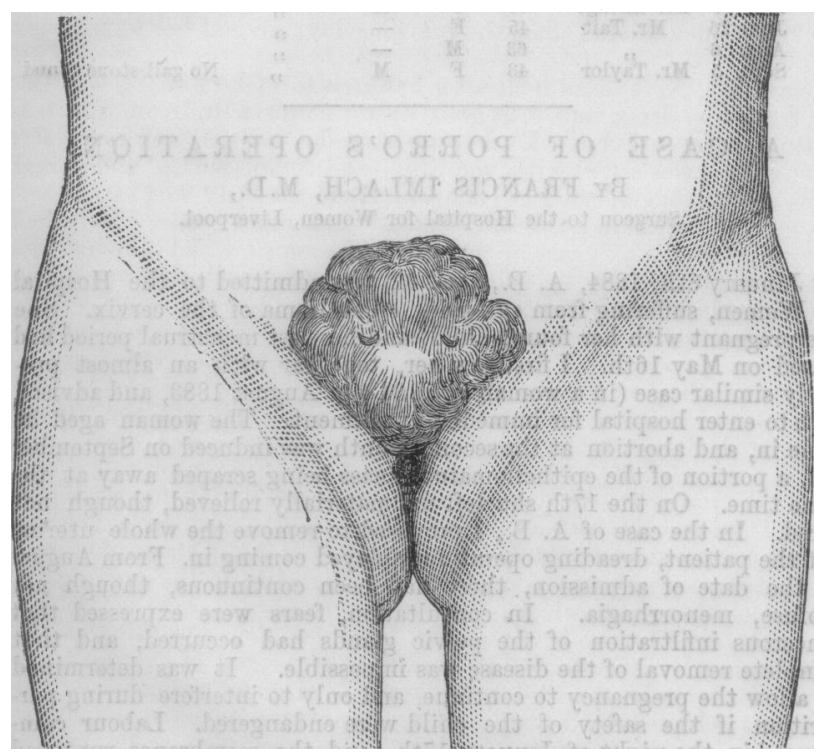

Fig. 1.-Original Condition.

from the lateral aspects of the abdomen, and twisted inwards on their attachments, so that the raw surface came into contact with the raw surface of the first mentioned square flap. When secured in position, the flaps entirely covered the vesical surface. The edges of the exposed surfaces on the abdomen were drawn together, and secured by hare-lip pins and sutures.

The temperature reached $103^{\circ}$ on the evening of the day following operation, but was not afterwards noteworthy. The flaps united by primary union; but the surfaces from which they were taken became exposed by retraction of their margins (the tension was great), and had to heal by granulation. During the process of healing, retraction of the flaps, especially of the side-flaps, drew upward the lower margin of the square flap, exposing its cutaneous surface, and bringing into view a corresponding portion of vesical surface. Therefore, on May 15th, Mr. Robson decided to perform a second plastic operation. The prominent folds of integument forming the labia majora were incised for three inches vertically; and from the upper end of these cuts, incisions were carried outwards, so as to allow two triangular flaps of skin to be slid upwards. The square flap of skin made in Wood's operation was loosened at its attachment to the pyriform lateral flaps, and turned downward, so that the cutaneous surface again covered the bladder mucous membrane. The newly made groin-flaps were approximated toward the middle line, covering the raw surface, and

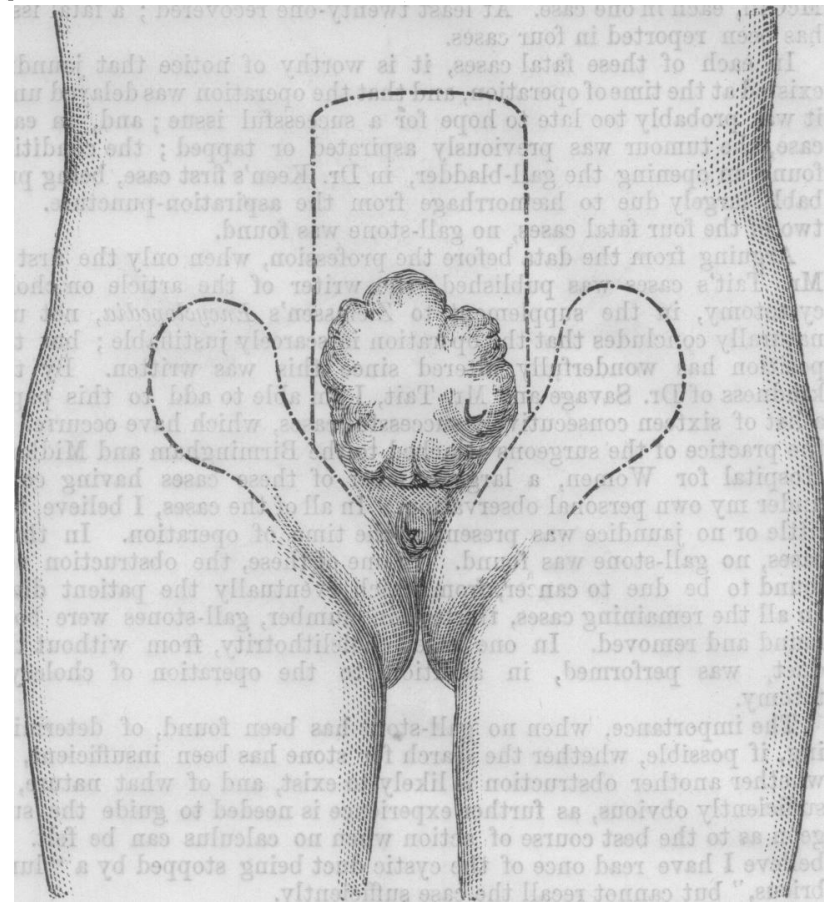

Fig. 2. - First Operation, March 1st. Incisions marked.

secured for an inch and a half in apposition; while the upper margins were sutured to the newly refreshed lower margins of the pyriform flaps of Wood's operation. Hare-lip pins and sutures secured the parts; dressings of carbolic oil were used. Union took place by first

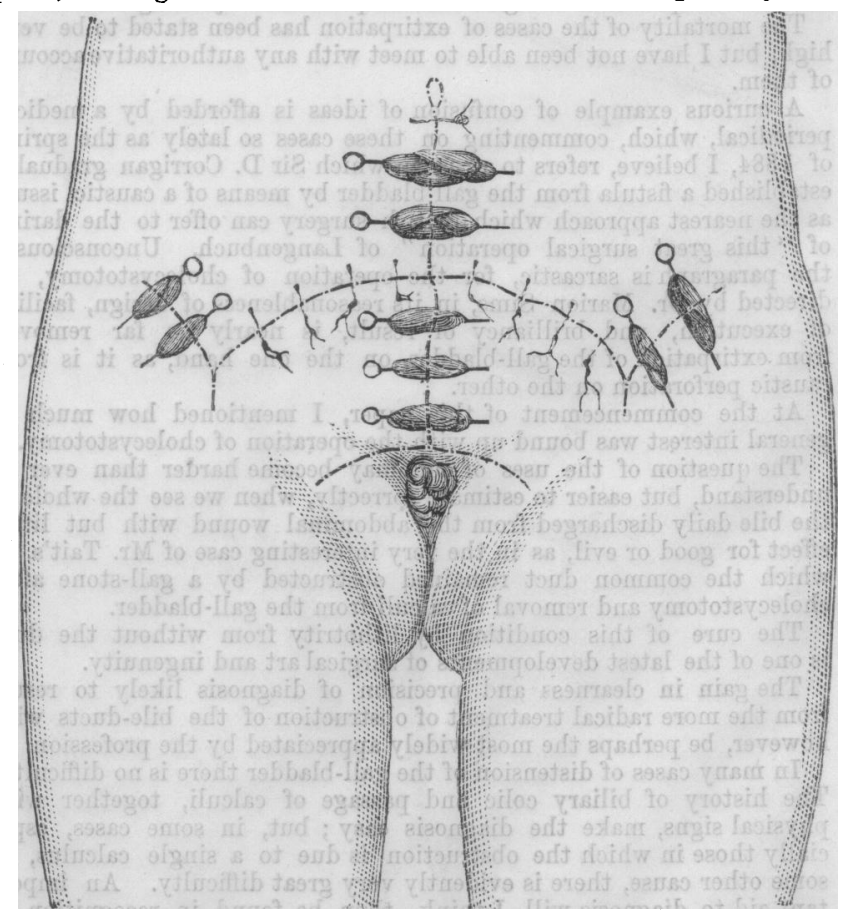

Fig. 3.-Appearance after Operation, March 1st.

intention. Some excoriation of the lower part, due to urine passing over it, was allayed by a weak alkaline lotion. The child's knees and hips were kept flexed for some time after the operation, to relieve the 
tension on the integuments of the groin. When all had healed, no bladder-surface was visible; a slit between two surfaces of skin, in the usual situation of the labia, formed the exit for urine. A portable nrinal was fitted before the child left the hospital.

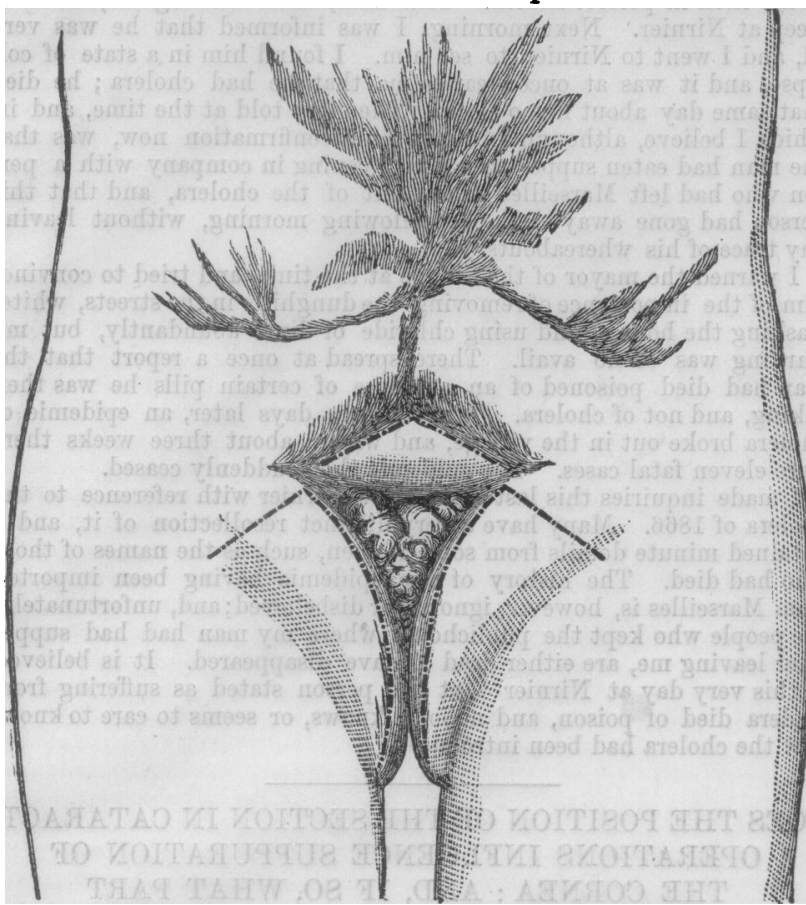

Fig. 4.-Condition of case on May 15th, showing retraction of flaps and exposure of vesical surface. The diagram also shows the lines of incision in the second operation May 15th.

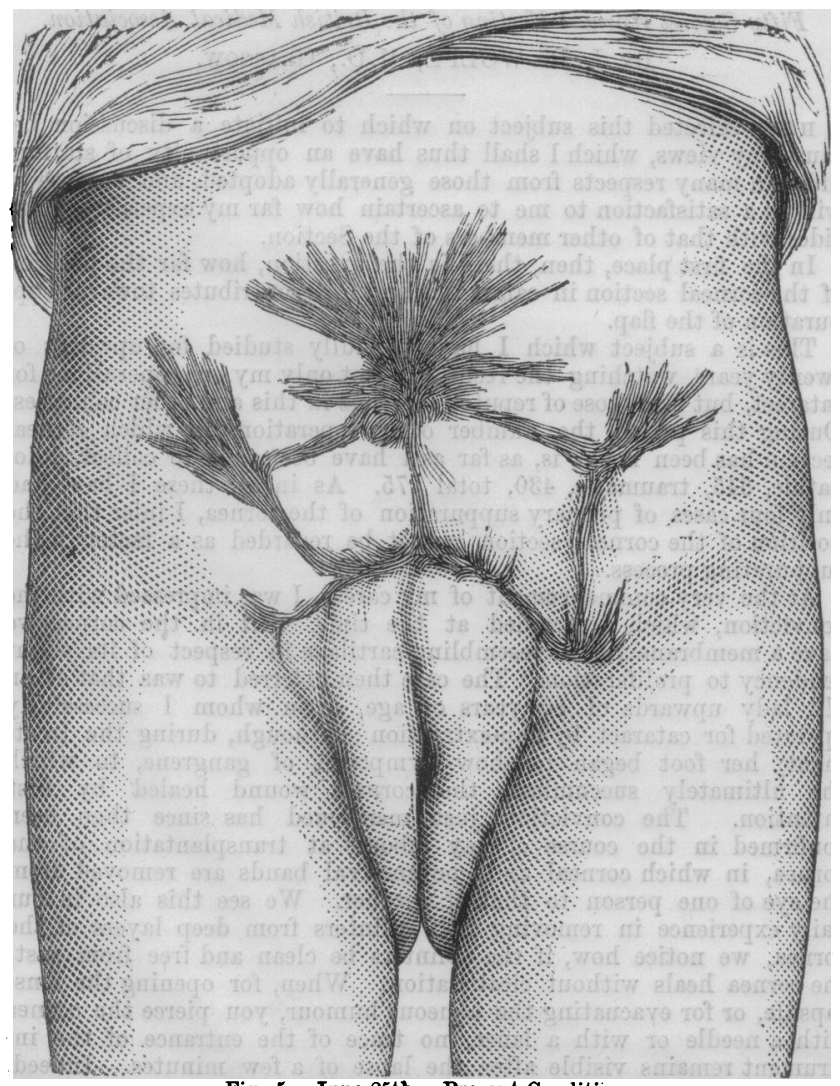

REMARKS BY Mr. ROBSON. - The accompanying drawings, skilfully executed by Mr. Child, very accurately represent the different stages of the case. As shown in Fig. 4, the patient would have left the hospital very little relieved by Wood's operation alone; but the additional plastic operation, by which flaps were obtained from the valva and slid upwards, without detachment below, gave the good result shown in Fig. 5, which condition must be permanent, as no amount of retraction can expose the bladder, the attachment of the flaps being opposite the direction of the retracting force.

\section{A CASE OF CHOLERA, ILLUSTRATING THE SUCCESSFUL EFFECT OF PRECAUTIONARY MEASURES IN PREVENTING THE SPREAD OF THE DISEASE.}

\section{BY C. DAVI D, M. D., of Geneva. ${ }^{1}$}

Mrs. X., 30 years of age, very much affected by her coachman's sudden death from cholera, left Marseilles on July 25th last, with all her family, in order to escape from the epidemic. She had been troubled with some slight diarrhœea, and her medical attendant had advised her not to remain at Marseilles.

She arrived at Geneva on July 27 th, and proceeded, at once, with her husband, to try to find an empty house. Thus she came to Versoix (a village at the lake-side, on the west shore, about five miles from Geneva), exhibiting at the time no external signs of disease. After visiting an empty villa in that place, she took it, and went back to Geneva for the night.

On July 28th, in the afternoon, she returned to Versoix with her family, consisting of eleven persons ; and the owner of the villa, finding her looks much altered since the previous day, advised her to send for me.

I saw Mrs. X. half an hour after her arrival. She was still wearing her travelling-dress, and had gone upstairs into a bedroom she was destined never to leave. During my visit she had several rice-water evacuations, was seized with romiting, and complained of abdominal pains and cramps in the legs; temperature of the body $36.4^{\circ} \mathrm{C}$; there was much emaciation; she had a small and rapid pulse. This had every appearance of a case of cholera. As soon as I had quieted the patient with reference to police-measures, with which she was afraid to be troubled, and I had assured her she would not be taken by force to the hospital, she acknowledged she had been ill the whole of the night and previous day; the fear of the police had prevented her, so far, from calling in medical aid.

Drs. Girod and Prevost were called in consultation, but the disease terminated fatally. The diarrhœe and vomiting ceased during the night of the 29th-30th ; the temperature rose in succession to $38^{\circ}$ and $39^{\circ} \mathrm{C}$.; she was unable to overcome her state of emaciation and weakness; and she died on the 30 th at 2 P.M. Her intellect had remained unimpaired until the last few hours, when she fell into a state of stupor. There had been no passage of urine since the $27 \mathrm{th}$, in the evening.

This is to my knowledge, the only uncontested case which has occurred in Switzerland. It might have become, according to the views generally entertained at present, the origin of an epidemic focus ; fortunately this did not happen. The following were the measures adopted by myself and my colleagues to prevent such an occurrence, which, thanks to local circumstances, were easily carried out The villa, situated between the two villages of Versoix, is limited on one side by the high road from Geneva to Lausanne, and on the opposite side by the lake. It is at a distance of at least twenty-five metres from any other dwelling, and is screened off from the neighbouring houses and high road by a number of trees: In front of it is a meadow, reaching as far as the lake. The place is entirely surrounded by hedges and walls, which enclose it without a break. An avenue through a shrubbery for a distance of 100 mètres leads to the house, and there is a gatekeeper's lodge where the avenue branches off from the high road.

The patient's room was on the first floor, had no access into other rooms and communicated with the stair through a narrow passage.

Under such conditions, the precautions to be taken were obvious; and easy to carry out. It was necessary, as far as possible, to protect the members of the family and the servants, and prevent absolutely any contact between the people in the villa and the inhabitants of the village. As soon as the nature of the case had been ascertained, I had all the useless objects and furniture removed from the room ; next, at my request, the head of the family selected the persons who world 